\title{
ORDEN Y CAOS EN LA TRADUCCIÓN CREATIVA (ASPECTOS DE COHERENCIA TEXTUAL)
}

\author{
JUAN PEDRO GÓMEZ SÁNCHEZ \\ (Universidad de Murcia)
}

\begin{abstract}
The main aim of the present article is to approach the problems of stability, prototypicality, reorganization and virtuous self-organization in the lext of creative translation from a semantic-topological view.

The structural shape of texture relationships between the source language text and the target language text shows a chain of regulating mechanisms apart from the context.

Finally, the topological analysis of the translation of Lewis Carroll's Jabberwocky into Spanish has allowed us to have a geometric vision of the underlying morphological stability and its sense attractors.
\end{abstract}

\section{Sobre la estabilidad estructural del texto}

Una de las perspectivas más sugerentes para la observación de los fenómenos complejos del lenguaje es la perspectiva procesual - la del continuo o la indiscreción - que, frente al atomismo excesivo, la discontinuidad o la discreción de las perspectivas estructurales y generativas, permite nuevas interpretaciones de algunos problemas lingüísticos de carácter textual.

La concepción que del texto tiene Hjelmslev (1971: 39-47), como clase divisible en segmentos, conduce, de forma consecuente e inevitable, a un análisis componencial de los mismos. Por tanto, las relaciones y las dependencias se constituyen, tras la descripción de las partes, en objetivos fundamentales. Sin embargo, las pautas del estructuralismo y del generativismo chomskyano, propias del método hipotético-deductivo, que representan una metodología científica de altísima rentabilidad, no tienen por qué ser necesariamente excluyentes, debiendo 
posibilitarse, por parte de los analistas, las vías complementarias de una siempre amplia metodología integral ${ }^{1}$.

En el universo físico, la discontinuidad puede ser tanto la norma como la excepción; pero, qué duda cabe que, pese a la justificación de cualquier idealización en el seno de su teoría correspondiente, la homogeneidad de un modelo simple, uniforme y bien delimitado no siempre es trasladable a un modelo realista como lo es un texto, de carácter complejo y heterogéneo. Ya sea en un devenir gradual o en un cambio catastrófico, un texto se diferencia siempre de otro texto, al mismo tiempo se distingue de lo que no es un texto, al margen de sus constituyentes y de las relaciones simples que se puedan establecer entre los mismos.

Los diversos aspectos cuantitativos no pueden calcularse ni reducirse a expresiones matemáticas exactas, si bien la recurrencia de los aspectos cualitativos, su constancia presentativa, permite determinar con cierta precisión dónde y cómo se llevan a cabo los tránsitos. El texto y su proceso ofrecen siempre un cierto tipo de estabilidad, una regularidad de la que se pueden deducir recurrencias identificables.

La estabilidad estructural, a la que tiende todo texto, implica rasgos cualitativos recurrentes, aunque las circunstancias que los hayan motivado sean muy diversas desde una perspectiva cuantitativa.

La agregación de fonemas, monemas, palabras, sintagmas y oraciones no es suficiente para determinar el concepto de texto ni el método de aproximación científica, que, en su caso, no será más que un método estructural de composición, basado en razones de carácter cuantitativo. No obstante, a la mecánica adicional y a la generación o bifurcación arbórea se opone un sentido último, que se manifiesta flotante en una estabilidad cualitativa. Así, los distintos conceptos sobre las configuraciones textuales funcionan como marcos, mapas o esquemas de los procesos cualitativos que los generan.

Un texto se manifiesta como un continuo entre dos vacíos, no admitiendo la identificación con otro texto por superposición topológica, salvo que esa superposición suceda consigo mismo en el mismo contexto y en la misma situación espacio-temporal.

La geografía del texto, conformada por elementos discretos íntimamente relacionados y cohesionados, es formalmente estable como constructo finito. Fonemas, monemas y oraciones configuran un edificio firmemente estructurado, pero el acceso al mismo, su recorrido, su disfrute, su entendimiento y rentabilidad pragmática, depende de las distintas variaciones adquiridas dentro de los distintos

\footnotetext{
${ }^{\prime} \mathrm{Al}$ respecto, resultan clarificadoras las reflexiones sobre propuestas teóricas y metodológicas llevadas a cabo por J. L. Cifuentes (1994: 10-13), con referencias de interés a las opiniones de Feyerabend, Gülich \& Raible y E. Ramón Trives.
} 
contextos espacio-temporales posibles.

En cada marco cosmológico, el texto actúa como una macrocategoría gramatical (al margen de cualquier dependencia de las categorías), pero con una cualidad fractal $^{2}$ (B. Mandelbrot, 1982) que suscita un cierto tipo de relación a escala de tenuidad creciente.

El amplio espectro verbal del sustantivo, las relaciones cualitativas del adjetivo y las capacidades cosmológicas del verbo determinan una escala de categorías dependientes de su profundidad. Evidentemente, un elemento categorial menos profundo se puede transformar canónicamente en un elemento categorial más profundo sin afectar a la significación. De esta manera, se puede sustantivar un verbo o un adjetivo, pero a la inversa es casi imposible (R. Thom, 1977: 340-341). Por su parte, el texto siempre es fruto de una textualización previa y, a su vez, se textualiza en cada contexto de recepción, pudiéndose también textualizar cada palabra o creoda (Ibíd., 1977; 131) del sistema de lengua y cada oración en su uso y contexto.

Los diferentes procesos de interpretación textual funcionan, por tanto, como catástrofes o cataclismos de un cambio de estado. Un mismo texto puede ofrecer valores culturales opuestos en contextos culturales opuestos. Por ello, un texto puede favorecer, en primer lugar, una aproximación interpretativa satisfactoria, correspondiente al sentido perseguido y a la intencionalidad emisora, o una aproximación interpretativa insatisfactoria, correspondiente a una posible construcción fallida. Desde otro punto de vista, y por desplazamientos culturales, puede favorecerse también una apreciación interpretativa impertinente, que se configurará como un sentido a la deriva muy distinto a las «alternativas inauditas" de manifestaciones no habituales (galimatías y sinsentidos). Una vez que la periodicidad de los sentidos ha dejado de percibirse de forma constante, el texto no puede por menos que tornarse azaroso ${ }^{3}$. El receptor del texto tiende a otorgar sentidos $\left(\left\{\sigma_{1} \pm \sigma_{2} \pm \sigma_{3} \pm \ldots \sigma_{\mathrm{n}}\right\} \subset \Sigma_{\mathrm{Td} \mathrm{x}}\right.$ ) que se van acumulando en la textura de un último sentido, finalmente otorgado o concluido por la posible interpretación

\footnotetext{
${ }^{2}$ Se entiende por fractal cualquier forma irregular, interrumpida o fragmentada, que sigue siendo así en cualquier escala que se someta a examen. Una dimensión fractal será la relación que se establece entre las distintas escalas. La característica más importante de la geometría fractal es la autosemejanza o sibisinilaridad, propiedad consistente en que «ada parte es igual que el todo pero en más pequeño».

Junto a la obra de Mandelbrot, resulta de interés por su claridad didáctica el texto-manual de Heinz-Oto Peitgen, Hartmut Jürgens, Dietmar Saupe, Evan Maletsky, Terry Perciante y Lee Yunker (1991). De carácter más técnico, pero muy preciso y esclarecedor, el libro de J. Feder (1988).

${ }^{3}$ «El texto es «azaroso» en función de la imposibilidad de especificar todas las variables internas de que depende cada texto concreto; pero es también «Azaroso» porque la naturaleza misma de esas variables hace imposible por principio definir sus valores en una situación específica.»(E. Bernárdez, 1995: 105) .

Podemos entender el azar epistemológico («azar»con minúsculas) como contingencia, error, ruido o ignorancia humana; el azar ontológico («Azar» con mayúsculas) como la contingencia pura (intuición incomunicable) que actúa ciegamente en el universo (J. Wagensberg, 1985; 67-69).
} 
global del texto. Sin embargo, esta acumulación no es aditiva sino integradora, fruto de múltiples relaciones desestabilizadoras entre los microtextos ${ }^{4}$, que tienden a mantener la individualidad de su sentido frente a los distintos textos de recurrencia extratextual, a los que se ven atraídos por la acción de nuevos y progresivos atractores de sentido.

Las estructuras sintácticas del texto son invariantes naturales que garantizan un cierto grado de estabilidad estructural en el sistema inestable del texto, que se fija en un contexto --dependiente de la recreación del receptor como aproximación ideal del contexto natural del destinatario- del que depende la progresiva integración de sentidos internos en forma recurrente.

El alto grado de invariancia de los componentes discretos del texto, su determinismo y predictibilidad no se constatan de forma similar en el cosmos del texto, aunque algunas invariancias prototípicas se repiten en ciertas situaciones comunicativas. Estas repeticiones, favorecedoras de estados de equilibrio, posibilitan una cierta estabilidad estructural sometida a variables de control.

Lo azaroso del texto, su independencia y creativa autonomía, le permite también, junto a una diferenciación antagónica, brusca y catastrófica, una diferenciación paulatina y gradual, dependiendo de los valores más significativos de las variables internas. Los espacios de nebulosa o de transición quedan explicados por la acción de las variables o por la intensidad de las saliencias léxicas, organizadas en campos y encuadradas en marcos discursivos.

El orden oculto del texto niega, por tanto, lo aleatorio de un sistema complejo, dinámico y abierto a través de estructuras profundamente codificadas.

\section{Re-organización y auto-organización virtuosa}

La labor traductora ha tenido tradicionalmente en la palabra y en la oración sus puntos de referencia inmediatos. Pero, estas formas inequívocas y categóricas sólo muestran una faceta muy restringida de la realidad comunicada. Parece evidente que los términos finales del diccionario, las entradas léxicas y sus articulaciones sintácticas son suficientes para establecer equivalencias discursivas aceptables. Sin embargo, el texto es una unidad mucho más rentable a causa de los patrones tipológicos que puede aportar al analista.

\footnotetext{
${ }^{4}$ En ocasiones, estos microtextos pueden ser coincidentes con los parágrafos, unidades subtextuales que facilitan la concentración de sentido y ayudan a los distintos procesos de relación cognitiva. «A menudo hay un grado razonable de correspondencia entre el párrafo, el tema del texto y su propósito retórico. Pero esto dista de ser siempre asís B. Hatim \& I. Mason, 1990: 226).
} 
Quizá fuera lo más cómodo para el traductor la existencia de una tipología textual que facilitara el tipo de texto con sus estructuras bien definidas 5 . Argumentaciones, análisis, descripciones, exposiciones, son tratamientos discursivos que responden a patrones muy delimitados, resultando fácil la transcripción superestructural y macroestructural del texto ${ }^{6}$. Algunos otros modelos estructurales se repiten en situaciones y contextos similares, con unas variables de formato, más o menos intensas, que pueden llegar a difuminar y a dificultar el ahormamiento tipológico de cada posible tipo de texto.

Algunos investigadores centran el punto de partida del diseño textual en el resumen (Hatim \& Mason, 1990: 234). Ya sean los resúmenes (abstracts) de carácter indicativo, informativo, de autor, de acceso, modular o informático, todos deben mostrar un alto grado de concisión y coherencia, fruto del análisis pormenorizado de los textos.

Las reglas de resumir (buen resumir) son normas que establecen el estilo y contenido de los resúmenes según las orientaciones de la American National Standard for Writing Abstracts. Con estas reglas, lo que se pretende no es tanto realizar la operación de extraer del texto original cuanto de condensar lo más posible, manteniendo las características esenciales del texto, sin que se distorsionen los puntos de referencia cognitivos que favorecen la coherencia textual originaria, como inferencias, implicaciones y presuposiciones $(\mathrm{H}$. Borko y C. L. Bernier, 1975; E. T. Cremmins, 1982).

Una visión sintáctica del discurso, en relación estructural de nuclearidadmarginalidad (A. Vera, 1994: 107-122), permite considerar las distintas articulaciones macroproposicionales de los niveles inmediatos inferiores o de composición secuencial ${ }^{7}$. Cualquier tipo de texto puede articularse en microtextos o ser coincidente, en una representación macroproposicional, con una predicación conceptual mínima del tipo interjección, enlace-término, apelativa o rótulo [ un

\footnotetext{
${ }^{5}$ Un tipo de texto con una prototipicidad muy densa y con un sistema firmemente estructurado facilita el análisis textual y su correspondiente equivalencia traductora. Ejemplos suficientemente significativos de planes compositivos textuales muy rígidos y de procesos analíticos de la designación del lipo se pucden consultar en J. P. Gómez, 1991 y 1993.

"Una superestructura es un tipo de forma del texto, cuyo objeto, el tema, es decir: la macroestructura, es el contenido del texto. Se debe comunicar, pues, el mismo suceso en diferentes 'formas textuales' según el contexto comunicativo» (T. A. van Dijk, 1978: 142) . «La formación de macroestructuras en un texto depende también de la información cognitiva (subjetivamente variable) de los hablantes (...) la asignación de macroestructuras no es sólo una operación basada en reglas, sino también estratégica.» (Ibíd., 288).

${ }^{7}$ «Una secuencia es una unidad de la organización textual, normalmente compuesta de más de un elemento, que sirve a una función retórica superior a la que cubren los propios elementos» (B. Hatim \& 1. Mason, 1990: 222). Los elementos son «las más pequeñas unidades léxico-gramaticales que pueden cumplir alguna función retórica, especialmente al servicio del propósito retórico global del texto» (Ibíd.: 221).
} 
enunciador dice: «\{¡Vaya! $\}, \quad\{$ PPor aquí! $\} \equiv\{$ iPasen! $\}, \quad\{$ iA la cama! $\}$, $\{$ Salida $\} \gg . .$. a un destinatario en un espacio y tiempo determinados /con o sin copresencia/ ]. En los textos más habituales y complejos la coincidencia formal de los constituyentes inmediatos con el parágrafo suele ser la norma, aunque semánticamente puede desplazarse y articularse en secuencias. A cada salto o desplazamiento de constituyente le suele corresponder también un cambio de asunto.

Por otra parte, junto a las unidades tangibles de traducción, las estructuras textuales abstractas, que varían de una cultura a otra, se configuran con perfiles muy individualizados; se amoldan a una tradición o a un sistema sociocultural, y se normalizan en un estado cuasi-estable.

Un texto, en cuanto sistema dinámico, se manifiesta como un estado en el que se reduce al mínimo la diferencia entre lo emitido por un productor y to comprendido por un destinatario, llegándose a la máxima coherencia cuando se alcanza un estado estable.

Qué duda cabe que el productor de un comunicado y el destinatario de un texto desean alcanzar un estado óptimo, y, aunque no se puede garantizar la identidad ni la correspondencia en la relación «producción $\rightarrow$ comprensión», se tiende al logro de un estado estable auto-regulado; estado que, por otra parte, en el texto escrito y en el monológico no es posible constatar.

En el caso del texto escrito, el productor se dirige a un receptor prototípico en un contexto prototípico. Las alteraciones o anomalías de un texto tipificado pueden ser el resultado de un proceso de producción alejado de la prototipicidad y, por tanto, de la coherencia general y de la bondad estructural.

Dentro del continuo comunicativo monológico y dialógico, la bondad tipológica y su adecuación reguladora van desde la oración reglada al texto estratégico de gran complejidad.

Por otra parte, en los límites del territorio gramatical, si toda la estructura fónica de un comunicado, en relación a su estructura semio-subyacente, «es una paráfrasis o traducción en potencia, en un proceso reversible» (E. Ramón Trives, 1983: 89), también es verdad que, en ocasiones, no todas las posibilidades del sistema fonológico son pertinentizadas morfológicamente. No obstante, en ciertos microtextos, elementos no pertinentes de los diversos niveles funcionan linguiísticamente ${ }^{8}$.

\footnotetext{
${ }^{8}$ Observable, de forma muy significativa, en el ejemplo sugerido por $F$. Lázaro Carreter y recogido por E. Ramón Trives (1983: 90) : «... de algún nivel debe proceder su pertinencia funcional. Lo que nos hace pensar en el caso de una combinación adecuada de fonemas que sin formante de pertinencia alguna morfológica, es proyectado directamente al nivel textual, en virtud de un «formante intertextual», transmitido por la memoria colectiva que dota del sentido textual de la /indiferencia/ al sinsentido morfo-léxico de «plin » en sintagmación inmediata con «a mí» en el microtexto «a mí plin».
} 
El fenómeno de la inadecuación fono-morfológica, por falta de pertinencia, y su correcto funcionamiento comunicativo, se repite, de forma similar, en otros niveles; sobre todo, en el léxico-semántico de ciertos pasajes de textos literarios.

En el texto creativo, las pertinencias propias de la comunicación denotativa - $-\mathrm{y}$ «connotativa habitual»-, se ponen a prueba, sometiéndose a suaves transformaciones progresivas, en la dimensión «práctica $\rightarrow$ estética»; o bien, se abandonan a catástrofes violentas, cargadas de renovación y reorganización. Los desvíos del paradigma lexemático se configuran, entonces, como alternativas inauditas (V. Lamíquiz, 1994: 63), sorpresivas e informadoras.

Pero, en cualquier caso, la reorganización y la auto-organización, además de mantener la estabilidad, generan nuevos desplazamientos interpretativos de carácter virtuoso.

Al margen de las variables textuales y de sus correspondientes contextos de traducción, en la práctica traductora se debe considerar el texto como un proceso energético, más que como un producto a consumir. Junto a las necesidades del destinatario, siempre ligadas a la intencionalidad productora original, se encuentran las expansiones significativas y de sentido, propias de la mecánica energética del texto concreto.

Por ello, cualquier tipo de manipulación, desvío, torcimiento o perífrasis en la traducción debe estar al servicio de los diversos propósitos comunicativos originales, considerándose las posibles relaciones de expansión semántica en cuanto al contexto.

Trasladada esta situación a los textos escritos más creativos, la coherencia del texto-destino, más allá de las fronteras lexemáticas, debe responder a formas que favorezcan la estabilidad estructural del tipo textual generado.

Los diferentes tipos de ruido, insertos en el texto como elementos comunicativos, se convierten en verdaderas distorsiones contracomunicativas ( $\mathrm{R}$. Barthes, 1970) que favorecen los estados estéticos de las configuraciones artísticoliterarias. La «equivocidad» y la subversión comunicativa son expansivas y, casi siempre, más excesivas que las propias intenciones del productor de mensajes.

Naturalmente, el ejercicio de la traducción se sitúa en el eje de un proceso interpretativo bicultural; proceso éste que comporta un producto textual acabado que, a su vez, se convierte en materia de gestión onomasiológica, para la generación de nuevos comunicados depurados de influencias evocativas personales, ajenas a la esfera de creación original. Empero, a la convicción del texto de salida coadyuva el cruce de referentes intertextuales que orientan el sentido (Beaugrande y Dresler, 1981: 182).

Además, las dominancias del propósito principal pueden enriquecerse, a través del campo léxico-semántico, con pregnancias motivadas por «ecos de sentido» y onomatopeyas secundarias (S. Ullman, 1970: 95-104). Y, así como la lexía, desde 
la más simple a la más compleja o textual, funciona como una unidad lexical memorizada (B. Pottier, 1975: 25), también su correspondencia requiere un encaje en la memoria cultural receptora.

La asepsia traductora, la traducción pura, es quizá la más difícil de las metas, dado que la conexión «productor $\rightarrow$ traducción $\rightarrow$ destinatario» está mediatizada por la «individualidad» (R. Barthes, 1973); una individualidad traductora y una individualidad destinataria que se descentran progresiva y consecutivamente en cada acto de lectura.

\section{CONTEXTO}

Relaciones culturales

Relaciones culturales

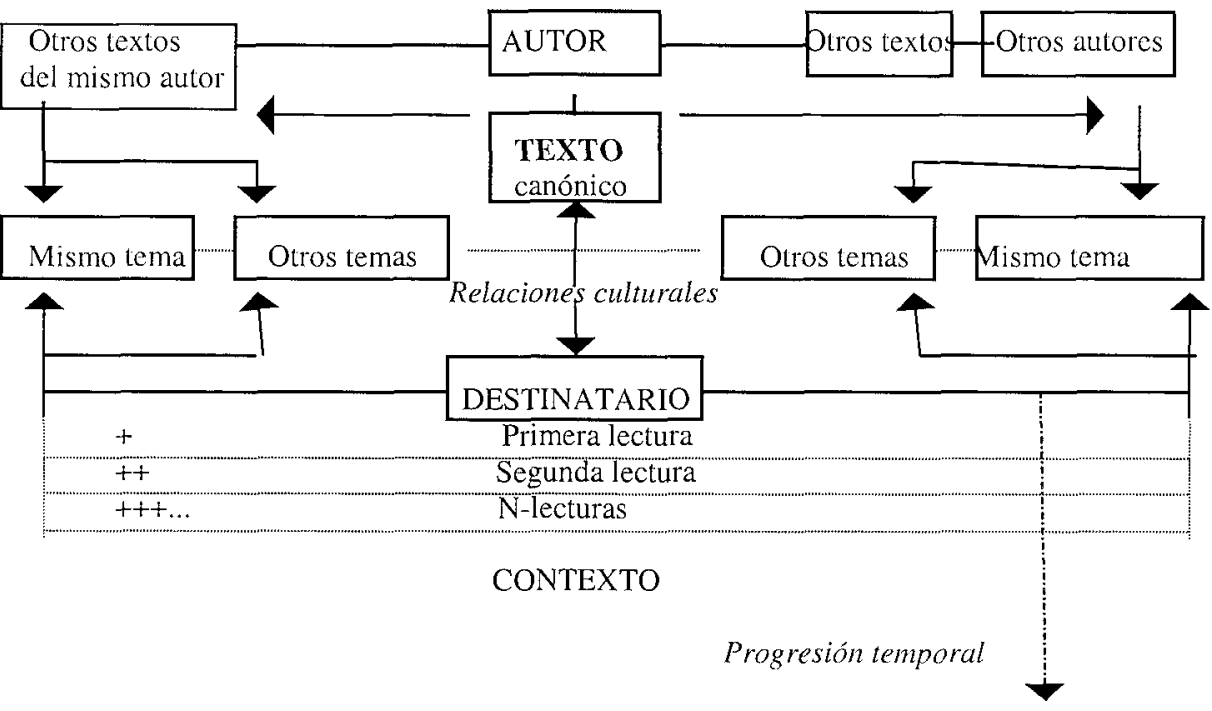

\section{Incertidumbre y regularidad operacional}

1. Lejos de las equivalencias precisas, la palabra no puede buscar su correspondencia exacta en la traducción, dado que se entrecruza continuamente con 
otras palabras dentro del conjunto textual, ampliando, a su vez, los círculos expansivos de connotación y sentido.

Las reglas de los niveles inferiores al texto condicionan la creatividad de éste, lo mismo que sucede con las interdependencias texto-mundo, que, en virtud de una relación social adquieren sentido y se clarifican.

El tamiz de la selección textual, la elección de elementos por parte del autor y la adecuación comunicativa al propósito inicial (V. Lamíquiz, 1994: 45-49) son aspectos intimamente trabados que otorgan corporeidad a la textura. La labor traductora reescribirá el texto repitiendo el proceso de selección en el sistema de la propia lengua, a la manera del creador original; después, se llevará a cabo el tratamiento y la adecuación temática, faceta en la que se reproducirá tono y estilo, en el intento de conseguir un nuevo estado de equilibrio lingüístico.

El texto poético resulta atractivo como banco de pruebas, tanto para comprobar los grados de transposición creativa, como para vislumbrar los mecanismos de autoorganización interna y sus correspondencias con el texto-destino. Indudablemente, puede resultar clarificadora una aproximación al texto poético, al margen de los intereses y objetivos de los profesionales de la traducción, para, desde una perspectiva textual, constatar la reconducción de mensajes a través de traslaciones del plan textual.

Frente a las estructuras conceptuales, más o menos universales ${ }^{9}$, a las que se pueden ajustar nuevas y paralelas estructuras traslaticias, las conceptualizaciones referenciales requieren una actividad de tipo heurístico. «A la estructura circular del significado textual corresponde una coincidencia plena entre interpretantes finitos y limitados. A mayor limitación del proceso semiótico, mayor equilibrio y menor ampliación del ámbito de sentido. Por el contrario, el texto como espiral virtuosa, desplazándose ligeramente en sus relaciones de sentido, puede generar un sistema azaroso improbable y original» (J. P. Gómez, 1995, e. p.).

El estado de no-equilibrio de la creación literaria es fuente de coherencia y organización en todos los niveles. El texto poético es creador como la misma naturaleza, y no se encuentra ubicado en el extremo de una escala de desviación lingüística, sino en el mismo núcleo de la naturalidad. La esencia de la naturaleza humana es fundamentalmente creativa, tanto en los inventos técnicos como en los intelectuales y artísticos ${ }^{10}$.

\footnotetext{
${ }^{2}$ Los modelos cognitivos idealizados (organizaciones de la sustancia del contenido) representan organizaciones concretas del conocimiento; necesarias para la comprensión de significaciones.

«Un M. C. I. (modelo cognitivo idealizado) es equivalente a los marcos de Fillmore o Minsky, espacios mentales de Fauconnier, esquemas de Talmy o Rumelhart, escenarios de Schank y Abelson, y dominios cognitivos de Langacker. Podemos entenderlo como un tipo de conocimiento base o complejo conceptual estructurado relativo al cual una noción es caracterizada.» (J. L. Cifuentes, 1994-95: 441).

10 «Toda invención, «humana» o natural, introduce en el mundo entidades que no existían, realizaciones y problemas nuevos; ¿en qué condiciones se producirán estas invenciones, en qué condiciones podrán
} 
Los llamados disparates poéticos, poemas del absurdo o sin-sentidos, son un reto para las aplicaciones metodológicas y las perspectivas analíticas del noequilibrio.

El poema denominado Jabberwocky es el texto nonsense más conocido de toda la literatura inglesa, $y$, como disparate poético resulta muy atractivo para analizar las relaciones entre construcciones léxicas inexistentes, absurdas cadenas fónicas que evocan significados auténticos, estructuras sólidas subyacentes y sentidos perfectamente definidos.

A partir de la lengua de comunicación, Lewis Carroll genera una turbulencia subversiva de la que surgen nuevas reorganizaciones, con un potencial tan intenso que se acrisolan de inmediato, llegando a incorporarse al lenguaje corriente y al diccionario.

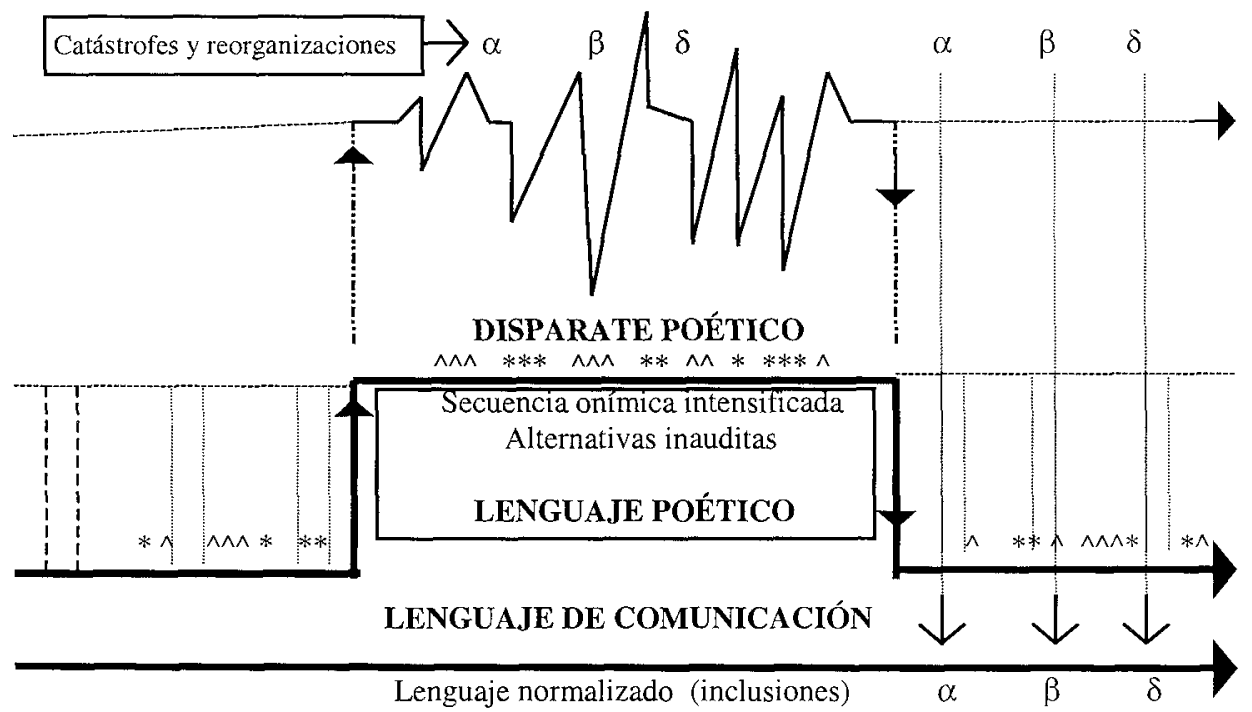

2. «Es como si me llenara la cabeza de ideas, jsólo que no sabría decir cuáles son!

En todo caso, lo que sí está claro es que alguien ha matado a algo...»

Así, se expresaba Alicia tras haber leído el poema Jabberwocky reflejado en el espejo. El poema le parecía «bonito» a la niña, pero era algo difícil de comprender.

mantenerse y provocar la destrucción o la conmoción del sistema en que se produzcan? Estas son las preguntas que plantean los mutantes producidos por la naturaleza y los inventos técricos e intelectuales del ser humano» (I. Prigogine, 1972-1982: 83). 
Pese a una semiosis dificultosa, se desprende de la composición una apreciable belleza. Como reconoce Humpty Dumpty, se trata de «un buen montón de palabras difíciles»; pero la construcción del texto responde a estrategias perfectamente diseñadas.

Al margen de la crítica literaria y sin entrar en los dominios propios de la traducción especializada, desde una perspectiva semántica-topológica, el análisis comparado de algunas traducciones del texto inglés a la lengua española puede poner de manifiesto las pulsiones y las fuerzas obligadas de una reorganización permanente, constantes en el seno de una turbulencia significativa.

Para el análisis que se va a llevar a cabo, se utilizará la versión original inglesa y varias traducciones españolas ${ }^{11}$.

\author{
JABBERWOCKY \\ ' $T$ was brillig, and the slithy toves \\ brillig, and the slithy toves \\ Did gyre and gimble in the wabe: \\ All mimsy were the borogoves, \\ And the mome raths outgrabe. \\ Beware the Jabberwock, my son! \\ The jaws that bite, the claws that catch! \\ Beware the Jubjub bird, and shun \\ The frumious Bandersnatch! \\ He toock his vorpal sword in hand: \\ Long time the manxome foe he sought... \\ So rested he by the Tumtum tree, \\ And Stood awhile in thought. \\ And, as in uffish thought he stood, \\ The Jabberwock, with eyes of flame, \\ Came whiffling through the tulgey wood, \\ And burbled as it came! \\ One, two, One, two! And through and through \\ The vorpal blade went snicker-snack! \\ He left it dead, and with its head \\ He went galumphing back. \\ «And hast thou slain the Jabberwock? \\ Come to my arms, my beamish boy!
}

\footnotetext{
${ }^{11}$ Hemos considerado de interés la traducción del Jabberwocky de Jaime de Ojeda (Alianza Editorial, Madrid, 1973) (Z); la de Ramón Buckley (Ediciones Anaya, Madrid, 1984, 1986, $3^{a}$ ed.) (Y); la de Luis Maristany (Plaza \& Janés, Barcelona, 1986) (P); y la versión de Ediciones Corregidor, Buenos Aires, 1973 (C).También hemos aportado nuestra particular versión (G), a fin de poder constatar más ampliamente las correspondencias y variables.
} 
O frabjous day! Callooh! Callay!

He chortled in his joy.

' $T$ was brillig, and the slithy toves

Did gyre and gimble in the wabe;

All mimsy were the borogoves,

And the mome raths outgrabe.

And, as in uffish thought he stood,

The Jabberwock, with eyes of flame,

Came whiffling through the tulgey wood,

And burbled as it came!

La versión española que servirá como punto de referencia general será la aportada por el autor de este trabajo (versión $« \mathrm{G} »)^{12}$ :

\section{JACARANDOTE ${ }^{13}$}

Ya vesperteaba, y las flexcosivas tovas

Girondaban y barreneaban por las céspolas;

Mismicosos se cimbreaban los borogovios,

$Y$ los rantamomios rugiflaban.

¡Guardaos del Jacarandote, hijo mío!

¡De las fauces que muerden, de las zarpas que agarran!

¡Guardaos del pájaro Jubojubo, y evitad

Al frumioso Bandagarro!

Empuñó su gladio vorpal:

Persiguió largo tiempo al enemigo manxón...

Después, descansó bajo el árbol Tumtum,

Y permaneció un rato reflexionando.

¡Y, cuando estaba en rigoroso pensamiento,

El Jacarandote, con ojos de fuego,

\footnotetext{
${ }^{12}$ Versión del Jabberwocky del autor de este estudio, sobre traducción y notas de Adelina Gómez, a la que agradecemos las muy oportunas observaciones sobre los problemas del inglés de época y las evocaciones fonéticas correspondientes, así como sus consideraciones sobre la disposición de las rimas abrazadas y encadenadas.

${ }^{13}$ Muchas de las traducciones mantienen el nombre original, Jabberwocky; otras, se adaptan lo más posible al significado del verbo inglés jabber («farfullar», «hablar mucho y confuso»). Así, la versión « $Z$ " la denomina Galimatazo (< «galimatías»). En la versión «Y» se opta, muy agudamente, por el término Fablistanón (< «fablistanear», antiguo verbo < «fablistá»: «charlar», «hablar mucho y con impertinencia»). En la versión «G» hemos optado por el nombre Jacarandote, atendiendo al significado, a la forma expresiva y a la connotación caballeresca $\left(1^{\circ}<\right.$ «jácara»< ára, yâkkara: «hacer rabiar», «molestan». $2^{\circ}<$ las cinco primeras acepciones del Diccionario de la R. A. E.: «canto desenfadado, alborotador». $3^{\circ}<$ «jacarandana»: fem. germanía: «Rufianesca o junta de rufianes o ladrones»; germ.: «Lenguaje de los ruftanes». $4^{\circ}$ «-ote»: a. aumentativo; b. connotación caballeresca $\equiv$ «Lanzarote», «Quijote». Posibles nombres, desechados por su complejidad: Jacarabarbarote y Jacarabarbarullo).
} 
Vino rechiflante por el bosque turgal,

Y barboteó al llegar!

¡Un, dos, un, dos! ¡De pies a cabeza

Lo tijereteó el gladio vorpal!

Muerto le dejó, y con su cabeza

Volvió galompando.

«Y habéis dado vos muerte al Jacarandote?

¡Venid a mis brazos, resplandeciente joven!

¡Oh, fralegroso día! ¡Jojorojó, Jajá!»

Carcajeó en su alegría.

Ya vesperteaba, y las flexcosivas tovas

Girondaban y barreneaban por las céspolas;

Mismicosos se cimbreaban los borogovios,

Y los rantamomios rugiflaban.

En una primera aproximación al texto, se puede constatar la existencia de una serie de entidades que, en un marco espacio-temporal, manifiestan unos comportamientos valorables emotiva y éticamente.

\section{ESQUEMA DE COMPORTAMIENTOS}

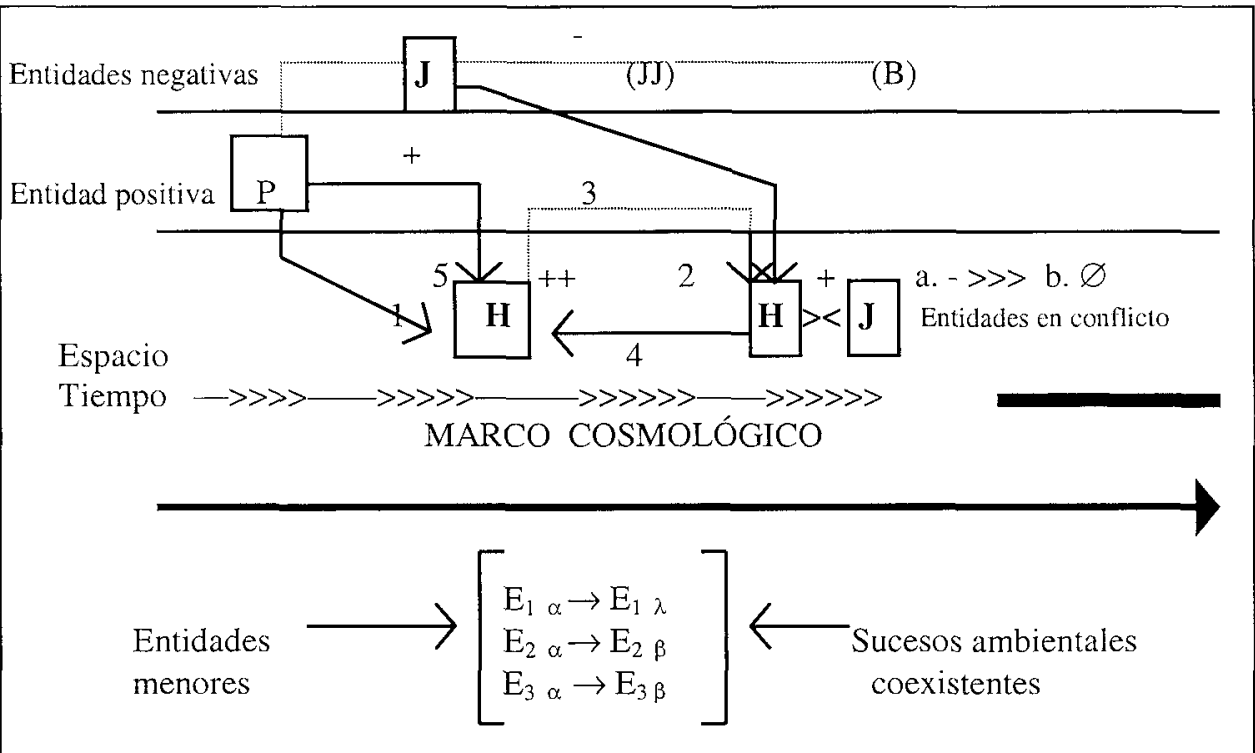


Resulta evidente que tras un liminar de apertura, en el que se simultanean diversos acontecimientos menores ( $\alpha$ : propiedades, atribuciones; $\lambda$ : localizaciones; $\beta$ : actividades), y que se configura como marco general, tiene lugar una introducción en la que un padre aconseja y previene a un hijo contra diversos peligros personificados o encarnados. En un momento posterior, el joven opta por una persecución, después descansa y, cuando se encuentra desprevenido, es atacado por algo terrible.

El núcleo de la acción central está determinado por la lucha entre el joven y el ser terrible y la consecuente destrucción de la entidad malvada. Un epílogo expone el retorno del joven con la prueba de su hazaña y subraya la consideración paterna. Después se cierra la exposición con el mismo marco cosmológico que se inició.

También, mediante la articulación de actantes, predicados y circunstantes, en un ámbito de referencia greimasiana, se puede representar en forma de macroproposiciones la macroestructura del texto, siendo coincidentes con el planteamiento topológico:

En un MARCO GENERAL (actividades de actantes secundarios en un espacio y en un tiempo) ACONTECE que:

$\underset{\text { Tiempo } 1}{\text { ALGUIEN }_{1} \text { Enuncia (apela, previene vs elementos disfóricos) algo a ALGUIEN }}$

ALGUIEN $_{2}$ Actúa (contra elemen. disfóricos menores)

ALGUIEN $_{2}$ Deja de actuar (descansa: actividad mental: reflexiona)

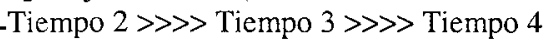

ALGUIEN/ALGO 3 (disfórico profundo) Se presenta, intenta actuar, intenta enunciar Tiempo $4 \gg \gg>$ Tiempo 5

$\mathrm{ALGUIEN}_{2}$ Enuncia y Actúa (contra ALGUIEN/ALGO ${ }_{3}$ (mata a ALGUIEN/ALGO 3 )

$\stackrel{\text { ALGUIEN }_{2} \text { Actúa nuevamente (regresa con testimonio de su valor) }}{\text { Tiempo } 5 \gg \gg>\text { Tiempo } 6 \gg \gg>\text { Tiempo } 7}$

ALGUIEN $_{1}$ Enuncia (constata, apela, felicita, expresa emociones eufóricas) a ALGUIEN 2 Tiempo $7 \gg \gg\left(\left(\right.\right.$ Tiempo $\left.\left._{11}\right)\right)$

Todo ello reformulado macroproposicionalmente como:

$/ /$ «ALGUIEN-H en un MARCO espacio-temporal es prevenido por ALGUIEN-P contra ALGUNOS seres terribles (en número de 3: J, JJ, B). ALGUIEN-H destruye a ALGUIEN/ALGO-J y ALGUIEN-P felicita a ALGUIEN-H.»// 


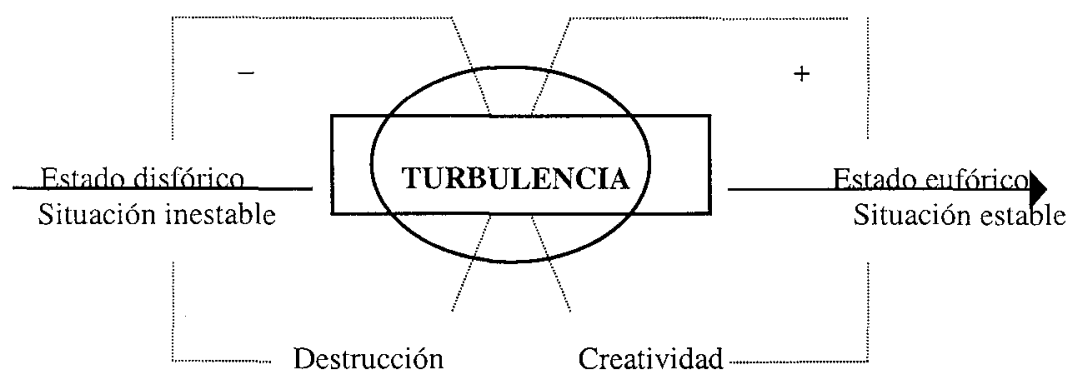

El enfoque narratológico centra el núcleo de la acción en el $4^{\circ}$ tema del cuento maravilloso según R. M. Volkov (V. Propp, 1977: 20), que reza «el héroe combate contra un dragón», simplificándose todo el proceso del folk-tale en la función «héroe se enfrenta a dragón y lo vence». No obstante, pese a la reducción funcional, el poema insinúa y condensa otras cinco funciones previas a la catástrofe «muerte»: a. variable de la función «prohibición»: «prevención apelativa» $\left(2^{a}\right.$ estrofa); b. variable de la función «transgresión de la prohibición» ( $3^{a}$ estrofa); $c$. variable de la función «el héroe se va de su casa» ( $3^{a}$ estrofa); d. variable de la función «camino de las pruebas» ( $3^{a}$ estrofa); variable de la función «el auxiliar mágico» : «arma invencible» ( $3^{\mathbf{a}}$ estrofa).

Estas funciones se inscriben secuencialmente en una estructura de acción muy compacta, en la que se ha suprimido la casi totalidad de motivos o mitemas de carácter marginal (J. Villegas, 1973):

Secuencia $0_{1}$ : Marco cosmológico con entidades y sucesos menores.

Secuencia $1:$ El héroe es avisado y prevenido

/Ambientación espacio-temporal

Secuencia 2 : El héroe no hace caso al aviso

/ Iniciador y Prohibición (?)/

El héroe se marcha de casa

El héroe empuña la espada mágica

El héroe se enfrenta a pruebas

Secuencia 3 : El héroe medita

/ Descenso a los infiernos /

El dragón aparece de súbito

El héroe vence al dragón

Secuencia 4: El héroe vuelve a casa con su trofeo /EI regreso con trofeo/

El héroe es felicitado

(adición de fórmulas humorísticas)

Secuencia $\mathrm{O}_{2}$ : Marco cosmológico con entidades y sucesos menores.

/Vuelta a la normalidad/

Todos estos motivos fundamentales del relato mítico se encuentran articulados 
en siete estrofas dispuestas simétricamente, según las formas expresivas dramáticas y narrativas; así:

$1^{\mathrm{a}}$. Presentación (marco general de ambiente)

$2^{\mathrm{a}}$. Dramatización (Yo-a-Tú. Tiempo presente ${ }_{\mathrm{A}}$ )

$3^{\mathrm{a}}$. Narración (un narrador extradiegético cuenta)

$4^{\mathrm{a}}$. Narración (un narrador extradiegético cuenta)

$5^{\mathrm{a}}$. Narración (un narrador extradiegético cuenta)

6. Dramatización (Yo-a-Tú. Tiempo presente ${ }_{B}$ )

$7^{\mathrm{a}}$. Cierre (marco general-ambiente)

$<$ Miedo $>$

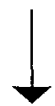

$<$ Alegría $>$

Todos los sucesos habidos en el seno de cada secuencia confluyen en el núcleo catastrófico «muerte», que se haya situado en el eje evolutivo «miedo $\rightarrow$ alegría». Hasta la ocurrencia del fenómeno catastrófico, se acumula un alto potencial de significación negativa que sólo se verá neutralizado por la propia catástrofe y reforzado por las fórmulas humorísticas.

Así pues, sin entrar en los problemas léxicos concretos, diferentes estructuras de comportamiento, acción, narración y expresión resultan suficientemente convincentes respecto a la coherencia global del texto. Las diferentes geometrizaciones permiten comprobar la existencia de circunstancias en las que ciertas entidades actúan sobre otras cambiando las situaciones. Funciones, simetrías y antagonismos revelan las zonas referenciales del texto original, dejando al aire, claros y disponibles, los perfiles fijos del entramado textual. La acción traductora encontrará en estos perfiles las pautas más severas y rigurosas para desarrollar el cuerpo y el estilo de las diversas versiones; variables textuales que, en todo caso, se habrán de manifestar regulares y similares tras la incertidumbre de sus superficies morfosintácticas..

3. La primera estrofa de Jabberwocky llama la atención de forma especial por una acumulación excesiva de términos difíciles de entender o imposibles de localizar en las entradas de un diccionario.

Las cinco acciones que se detectan son imposibles de traducir de forma directa y sólo pueden adquirir sentido por las relaciones compositivas, por los desplazamientos onímicos, por las explicaciones de Humpty Dumpty o por las glosas de Carroll.

'T was brillig, and the slithy toves

Did gyre and gimble in the wabe:

All mimsy were the borogoves,

And the mome raths outgrabe.

Sin embargo, esta secuencia introductoria microambiental «suena» a verdadera 
pese a su dificultad; dificultad a la que coadyuva la oscuridad léxica de los sustantivos y modificadores adyacentes.

Viejas raíces anglosajonas, palabras inventadas, palabras irreproducibles, palabras explicadas, pero contradictorias con explicaciones de otros textos del propio autor: un auténtico galimatías difícil de desentrañar y mucho más de traducir.

\section{VERSIÓN «Z»}

Brillaba, brumeando negro, el sol: agiliscosos giroscaban los limazones banerrando por las váparas lejanas; mimosos se fruncían los borogobios mientras el momio rantas murgiflaba.

\section{VERSIÓN «C»}

Calentoreaba, y las viscotivas tovas vuelteaban y tregujereaban el terecho.

Misébiles estaban los borogovas y los deros trugones bramastoilbaban.

\section{VERSIÓN «Y»}

Borgotaba. Los viscoleantes toves rijando en la solea, tadralaban... Misébiles estaban los borgoves, y algo momios los verdos bratchilbaban.

\section{VERSIÓN «P»}

Era cenora y los flexosos tovos en los relonces giroscopiaban, perfibraban. Mísvolos vagaban los borogovos y los verdirranos extrarrantes gruchisflaban.

\section{VERSIÓN «G»}

Ya vesperteaba, y las flexcosivas tovas

Girondaban y barreneaban por las céspolas;

Mismicosos se cimbreaban los borogovios, Y los rantamomios rugiflaban.

Las cinco versiones difieren, lógicamente, en el tratamiento léxico, en alguna estructura sintáctica y en el ritmo de rima, pero son básicamente coincidentes en el esquema estructural (EE), que actúa como un poderoso atractor que estabiliza y fuerza un modelo definitivo. 
EE «t" (Componentes del enunciado):
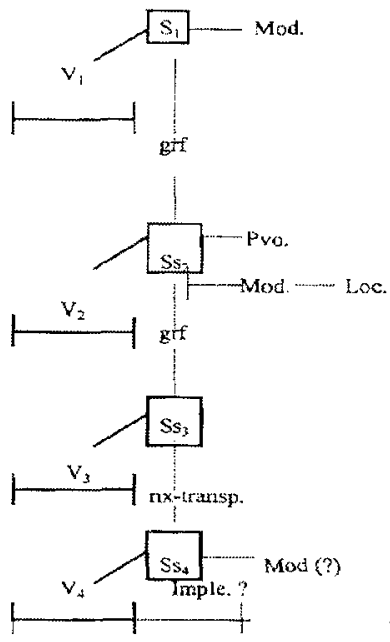

Efe $\ll$ Co (Componarites dal enunciado)
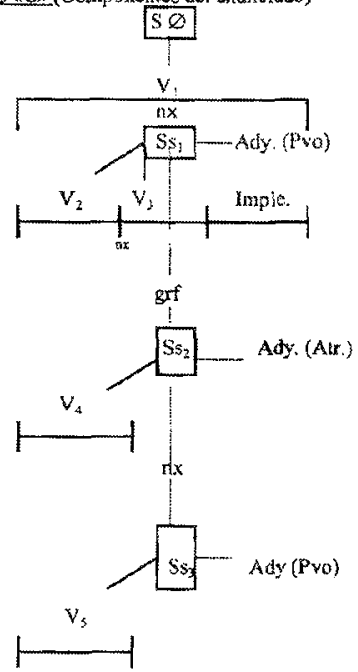

EE $\ll X_{3}$ (Componentes del enunciado)

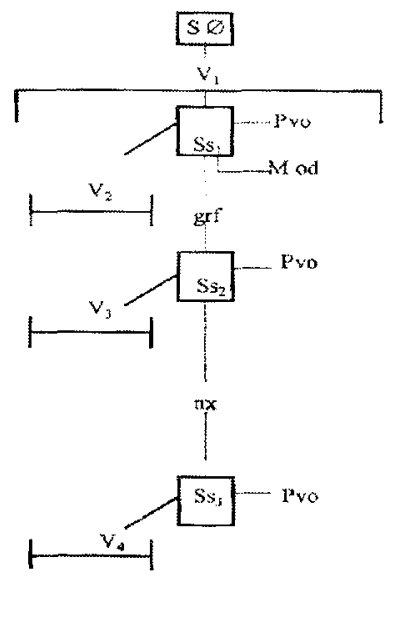

EE $\&$ P (Componantes del enunciado)

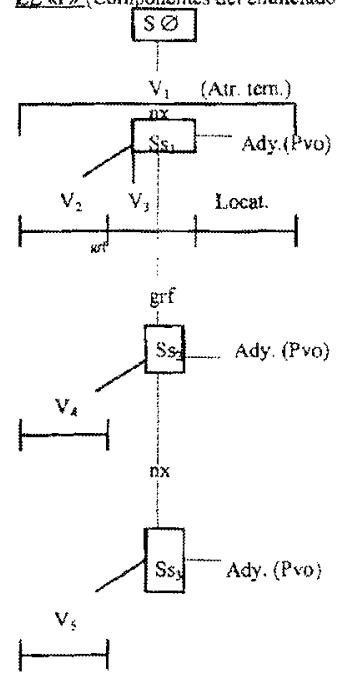




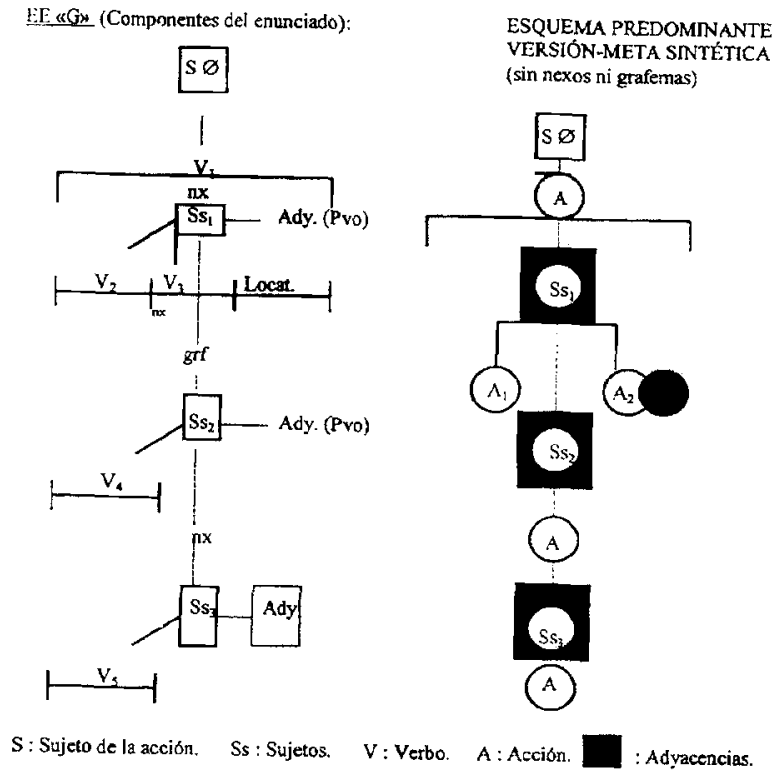

No hay duda de que la simetría radial del esquema predominante, síntesis de los cinco esquemas de las correspondientes versiones-meta, no sólo aclara las relaciones entre los elementos componenciales, sino que permite visualizar los grandes cauces reguladores de la atracción traductora.

En el plano léxico, una serie de expresiones (diez palabras de la versiones $\langle Z » y$ «G»; once palabras en la versiones $\langle Y »,\langle C » y\langle P »)$ funcionan de forma catastrófica en la percepción lectora, así como en las correspondientes conceptualizaciones del proceso semasiológico. Realmente, las coincidencias son muy significativas. Los dos desplazamientos de las versiones $\langle\mathrm{Z}\rangle \mathrm{y} \ll \mathrm{G}\rangle$ radican en la traducción normalizada de la palabra «mimosos» (mimsy) en la primera versión, y en la traducción sintética y ficcional de la palabra «rantamomios» (mome raths) en la segunda versión. Las correspondencias originales de la versión inglesa justifican ambas posibilidades.

Respecto a las demás expresiones, las semejanzas lexemáticas fuerzan la integración de sememas : 'brillig': $<^{*}$ brilliant $~ /$ magnífico, genial, brillante/ $\cap$ broil /asar, quemar/ (en la explicación de Humpty Dumpty. «eran ya las cuatro de la tarde, porque es cuando se encienden las brasas para asar la cena»); 'slithy': $<^{*}$ slim $\sim /$ delgado/ $\cap$ slime $\sim /$ lodo, cieno, baba/ $\cap$ slimy $\sim /$ viscoso/ $\cap$ slither $\sim$ 
/deslizarse/ $\cap$ lithe $\sim$ lágil/; 'gyre': < *gyaour=giaour $\sim$ un perro $\sim$ un infiel/ $\cap$ at. gyrus /movimiento circular, giro/; 'gimble': <* gimbal /eje anillado/ $\cap$ gimlet /barreno/; 'mimsy': <* miserable < mimserable /triste, infeliz, inseguro/ $\cap$ mime /mímical $\cap$ mimic limitador/ $\cap$ mimesis $\sim$ mimosis /mímesis/ $\cap$ mimosa /planta mimosácea, «mimosa púdica": sus hojas se contraen al menor contacto/ $\cap$ mimsey /remilgado/.

Las palabras fin de verso toves (ver. «Z»: «limazones»; ver. «Y»: «toves»; ver. «C»: «tovas»; ver. «P»: «tovos»; ver. «G»: «tovas»), wabe (<* swab: /limpiar con los movimientos que se imprimen a una mopa: «de aquí para allá2, como se mueve la hierba con el viento, como olas de césped/; ver. «Z»: «váparas»; ver. «Y»: «solea»; ver. «C»»: «terecho»; ver. «P $»$ : «relonces»; ver. «G borogoves (ver. «Z»: «borogobios»; ver. «Y»: «borgoves»; ver. «C»: «borogovas»; ver. «P»: «borogovos»; ver. «G»: «borogovios») y outgrabe (<* outgribe< ant. to grike o shrike > shriek, creak: /gritar, chillar, rugir/, /silbar/; ver. 《Z»: «murgiflaba»; ver. «Y»: «bratchilbaban»; ver. «C»: «bramastoilbaban»; ver. «P»: «gruchisflaban»; ver. «G»: «rugiflaban») son, al margen de las glosas en MishMash y de las explicaciones ficcionales, expresiones «inencontrables» o «cuasiinencontrables», lo que se pone de manifiesto en la respetuosa fidelidad lexemática y en la gran similitud de las adaptaciones de toves y borogoves, así como en la disparidad de las adaptaciones de wabe y outgrabe. Además, esta última expresión es entendida de dos formas diferentes en la versión «Z», que en la primera estrofa es traducida como «murgiflaba», siguiendo las variables del antiguo verbo to grike, y en la séptima estrofa como «necrofaba», siguiendo las variables actuales de out y graves («sacar de las tumbas», «comer»- «fuera de las tumbas»).

En el esquema aportado más abajo, se puede ver que en un primer nivel de recepción textual (I), las palabras «normales» marcan el proceso enunciativo como elementos de articulación sintáctica. Junto a estas palabras, toda una serie de depresiones señalan el cataclismo de las sucesivas subversiones y excrecencias léxicas, que, dada su construcción sobre raíces y palabras preexistentes, evocan auténticos significados (II), engarzándose a través de los estabilizadores o atractores morfológicos (III). Así, en este diseño topográfico del relieve textual correspondiente a la primera estrofa, se puede visualizar el efecto caótico de la creación literaria correspondiente a la versión «G» y la regularidad subyacente a la incertidumbre textual. 


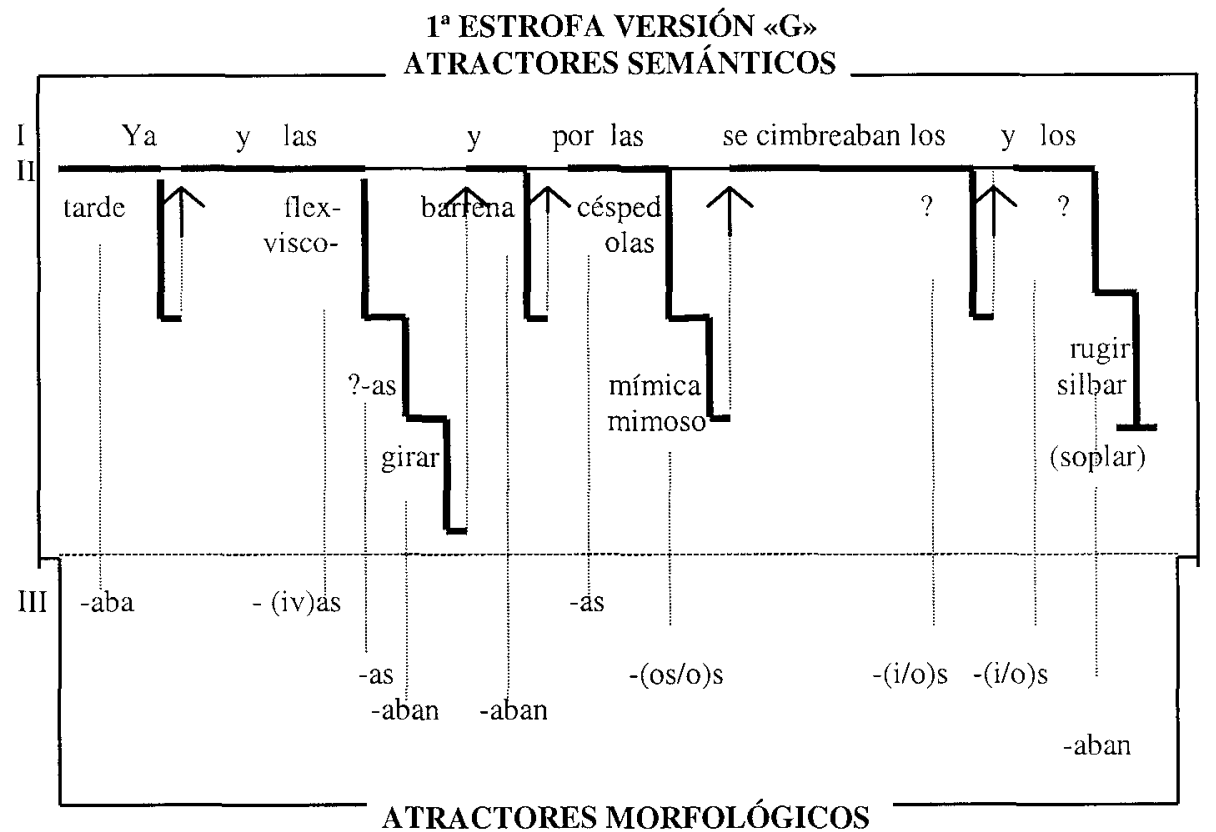

Evidentemente, las correspondencias léxico-semánticas no son elementos lingüísticos reales ni tienen referentes objetivos, pero en cada catástrofe ${ }^{14}$ se generan formas prototípicas aproximativas, inducidas por el plano fónico, las cuales reconducen el sentido. La acción traductora debe moverse, por tanto, en esas áreas de prototipicidad, en las que el mejor ejemplar se configura básicamente en función de la frecuencia. Por ello, algunas expresiones «inencontrables» responden al grado de frecuencia 0 , y sólo se pueden sustituir por adaptaciones fónicas de la lengua meta, así: toves: -os, -as; borogoves: -bios, -ovos, -ovas.

De igual manera que la elección verbal no es puramente pragmática, sino que viene forzada por constreñimientos semánticos procedentes de los procesos espacio-temporales y de las representaciones del mundo exterior (F. M. Pérez \& A. J. López, 1994-1995: 314), también los demás componentes de la estructura enunciativa, a través de las relaciones oracionales, manifiestan sus exigencias. En

\footnotetext{
${ }^{14}$ Entendemos aquí por «catástrofes» los cambios que acontecen en el comportamiento semiótico de un sistema; alteraciones capaces de mostrar la incesante transformación, destrucción y creación de formas. «Una catástrofe, en el sentido amplísimo que Thom le da al término, es cualquier transición discontinua que ocurre cuando un sistema puede tener más de un estado estable o cuando puede seguir más de un curso estable de cambio. La catástrofe es el «salto» de un estado o curso a otro» (A. Woodcock y M. Davis, 1989: 49).
} 
esta primera estrofa, se pueden deducir formas forzosas o magnéticas, de carácter gramatical, que sobrepasan la incertidumbre y que regularizan la comunicación:

1. Ya: ACCIÓN (V. imper., dependiente de la inmediatez)

2. $y$, las
A. a. N fem. / plu.
b. Ady fem. / plu.
B. a. $\mathbf{N}$ fem. / plu.
b. Ady fem. / plu.
C. $\quad$ ACCIÓN (V.: $3^{\mathrm{a}}$ per., plu.)

3. $y$ : a. [puede repetirse el esquema anterior o parte del mismo ]

b. ACCIÓN (V. : $3^{\text {a }}$ per., plu.)

4. por las: a. Locat. espacial fem. / plu.

b. Locat. temporal

5. <grafema> / pausación /

6. *se cimbreaban los
A. a. $\mathbf{N}$ mas. / plu.
b. Ady mas. / plu.
B. a. $\mathrm{N}$ mas. / plu.
b*. Ady mas. / plu.
$\begin{aligned} \text { 7. y los:A. a. } & \mathbf{N} \text { mas. / plu. } \\ \text { b. } & \text { Ady mas. / plu. } \\ \text { B. } & \text { ACCIÓN (V. } 3^{\text {a }} \text { per., plu.) }\end{aligned}$

Más allá de la singularidad y ejemplaridad de esta primera estrofa, la singularidad verbal dominante en el poema se concentra en las acciones relacionadas con los sucesos nucleares (B. Pottier, 1992): /vesperteaba/, que tiene un aspecto evolutivo, continuo u homogéneo; /persiguió/, que manifiesta un aspecto estativo de actividad y transitivo; ( $/$ se cansól, evolutivo causativo de continuidad )), /descansól, aspecto evolutivo; Imatól, que responde al esquema evolutivo, causativo (desaparición); y /fue felicitadol, aspecto idéntico al anterior, pero con proceso de aparición. Así pues, todo el caos (?) verbal y creativo del poema está atraído o magnetizado por un aspecto general evolutivo, emanado de la carga semántica de los lexemas verbales. Bajo la forma poemática, determinada por métrica original, la composición estrófica y la rima, la acción de los acontecimientos sigue un axis procesual evolutivo propio de la narración, aunque ésta se manifieste enjaulada en la estructura versal, a la manera del cuento poetizado (más preciso sería * poematizado) o de las composiciones epopéyicas y épicas. Todo, absolutamente todo, pasa, sucede, en el tiempo, y se conforma textualmente a través de recurrencias morfológicas cotextuales (tal como ocurre en la primera estrofa) y a través de una dominancia paratáctica continuada. Un tiempo caótico dentro de un tiempo histórico; un tiempo en el que, a través de la muerte, se transforma lo disfórico en eufórico, siempre dentro de un marco global de acción sostenida en el pasado. Un antes y un después inscritos en el ayer de la leyenda 
ficcional, continuamente revitalizado en el presente de la interpretación literaria.

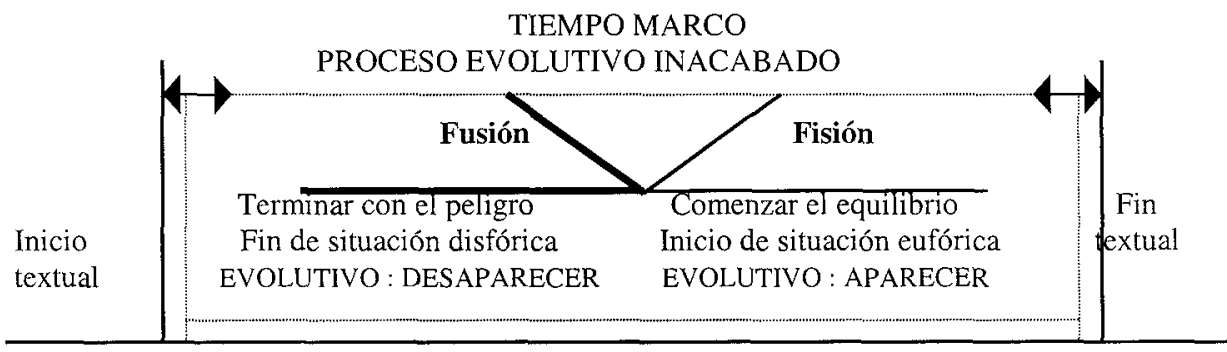

4. Por otra parte, son las interacciones semánticas entre conceptos las que imponen las relaciones sintácticas (René Thom, 1977). Por ello, aplicando a la singularidad verbal dominante las morfologías de significado arquetípicas (catástrofes elementales) $^{15}$, se constata que a partir de un despliegue cero, propio del concepto verbal «era» o «existía» se hace patente un /vesperteabal , marco temporal de una serie de actantes y circunstantes ambientales de máxima dificultad traductora. La acción de $\mathbf{P}$, que «aconseja» a $\mathbf{H}$, tiene la morfología de la donación y se configura como una catástrofe mariposa. Después, $\mathbf{H}$ /persiguiól tiene la morfología de la captura y se configura como una catástrofe cúspide (sobrevive $\mathbf{H}$, Sujeto de la estructura sintáctica SVO). Más tarde, como consecuencia del esfuerzo, $\mathbf{H}$ /descansól, lo que manifiesta una morfología bipolar de cambio, propia también de la catástrofe cúspide. Tras la aparición súbita del monstruo, $\mathbf{H}$ /matól al terrible enemigo, lo cual corresponde al esquema morfológico de la reunión, la captura y la separación, dado de nuevo en la catástrofe cúspide. Y, de inmediato, $\mathbf{H}$ le «cortó» la cabeza, morfología ésta de la excisión reflejada en la catástrofe umbílica parabólica; $\mathbf{y}$, por último, $\mathbf{H}$ /volviól a encontrarse con $\mathbf{P}$, lo que adquiere la morfología de una reunión en la catástrofe cúspide.

Parece evidente que, coincidiendo con la predominancia del aspecto evolutivo, la catástrofe verbal más representativa del poema sea la catástrofe cúspide, aplicable a la acción fundamental de la diégesis, que resuelve la turbulencia con un estado cualitativamente estable distinto al previo a la catástrofe.

\footnotetext{
${ }^{15}$ Las catástrofes elementales son arquetipos o modelos ideales de disposiciones tipológicas básicas, que sugieren informaciones diferentes sobre posibles comportamientos (R. Thom, 1977; A. Woodcock y M. Davis, 1989).
} 


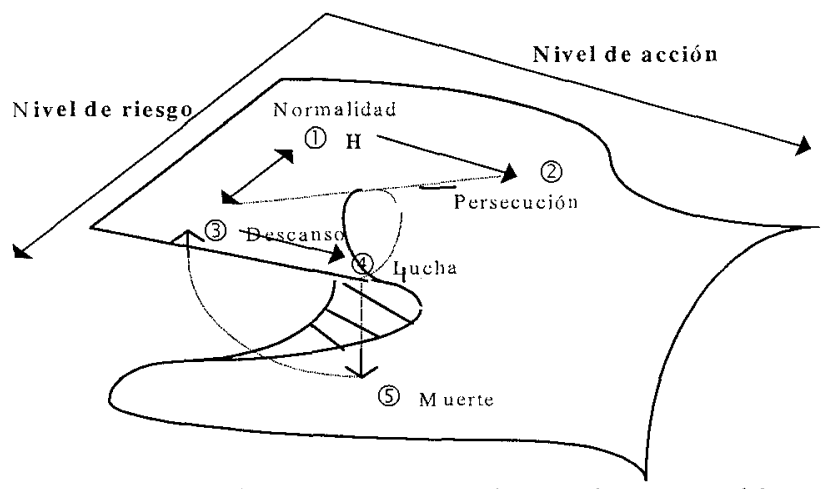

En el cuadro sintáctico, los términos creativos e inencontrables se comportan como saliencias ( $\mathrm{R}$. Thom, 1988: 19) levemente descolocadas respecto a sus fondos semánticos respectivos. Cuanto mayor es el desplazamiento, más difusa se torna la operatividad linguística, ya que la distorsión léxica debilita la recuperación semántica inmediata. En cierta forma, la persistencia catastrófica conduce a la interacción más intensa de los constituyentes. La turbulencia generalizada provoca tensión y ésta encuentra un primer escape a través de los cauces morfémicos. Sobre un fondo de improbabilidad general, el orden morfológico, estructuralmente reiterado, constituye un principio seleccionador que disminuye las ocurrencias posibles de desorden. Pero, la traducción creativa es, ante todo, reorganización. A la palabra hay que arrancarle el sentido, aunque sea «violándola» (P. Newmark, 1987: 54) y de esa violación surgirán nuevas posibilidades que se justificarán y legitimarán por exigencias internas del sistema de lengua en el texto concreto.

A mayor complejidad fonémica, léxica y semántica, mayor dificultad de entendimiento e interpretación, por lo que la intensidad de la creación tiende a decaer muy rápidamente. Un potencial exagerado de creatividad, en todos los niveles, sólo puede mantenerse en textos muy reducidos, tendiendo, de inmediato, a disiparse y a reorganizarse con formas más simples, o, en su defecto, provocando nuevos sentidos y coherencias contextuales del tipo «poemas del absurdo".

Slithy «flexcosivas», did gyre «girondaban» y gimble «barreneaban» son saliencias que destacan del fondo textual con un perfil muy delimitado y preciso, lo mismo que sucede con la saliencia toves «tovas», si bien en este último caso, el contorno es impermeable semánticamente para el destinatario y poroso para la acción pregnante de las saliencias dependientes de su núcleo. Este fenómeno se repite regularmente con el circunstante locativo in the wabe «por las céspolas»y con los dos núcleos restantes de la estrofa: borogoves «borogovios» y mome raths «rantamomios». Los nombres propios Jabberwock, Jubjub, Bandersnatch y Tumtum son formas cuyo interior se completa de manera diferente. El grado de 
completitud semántica de Jabberwock se inicia en su construcción léxica y se culmina en su relación catastrófica con el joven héroe, variando la intensidad significativa, su caudal sémico, a través del espacio y del tiempo narrativo, constituyéndose finalmente en prototipo de dragón verborréico. Los casos de Jubjub y de Tumtum son muy similares; carentes de connotación inmediata y opacos, a pesar de sus resonancias onomatopéyicas, se transfieren casi o sin variación, impregnados por el significado sustantivo de bird y tree, en un marco de tenebrosidad y peligrosidad, determinado por la acción sémica connotativa de Jabberwock, /jaws that bite/, /claws that cath/ y /frumious Bandersnatch/; todo ello junto a la exhortación temerosa desprendida del modus del actante-consejero, que, en íntima vecindad centrípeta, encuentra su complemento emotivo en la oposición simétrica y centrífuga de la sexta estrofa.

Los adyacentes y las acciones verbales restantes, de carácter inusual, son porosos para la acción de sus términos inmediatos y relativamente permeables para la interpretación de cualquier destinatario, ya que no ofrecen más dificultad que la que se desprende de cualquier técnica conceptista.

«Cuando yo uso una palabra... quiere decir lo que yo quiero que diga, ni más ni menos», dice Humpty Dumpty en su célebre discurso sobre semántica. Desde este entendimiento del uso de la lengua y de sus valores sígnicos, con la adecuación morfológica y la permeabilidad de las unidades léxicas inencontrables, la coherencia del texto-fuente está garantizada. Sin embargo, para el destinatario (aunque el productor del texto suponga en el lector ideal un mayor conocimiento del mundo y una gran capacidad lingüística) el grado de desconcierto será [es y debe ser] muy alto. La intencionalidad textual así lo requiere, a fin de cubrir las expectativas y conseguir los efectos previstos en la desambiguación contextual.

La jocosidad, la caricatura y la parodia se desprenden del engolamiento, del énfasis y del ridículo dramatismo, así como de las contextualizaciones intertextuales; pero no anulan ni desmerecen las dos grandes pregnancias del poema: el miedo y la alegría, que superan el artificio y hacen del lenguaje un servidor idóneo capaz de aplastar su más nefasta verborrea con una generación léxica efectiva y, en algunos casos, consagrada por el lexicón y la historia.

5. En esta aproximación textual que hemos llevado a cabo, mera introducción analítica a través de planteamientos caóticos y resoluciones estables, no se ha planteado la aplicación rigurosa de una teoría, sino el seguimiento de un método, incipiente y todavía no muy evolucionado, para efectuar «tanteos topológicos» y sugerir distintas visiones de coherencia textual en la traducción creativa. "Como insiste frecuentemente René Thom, la nueva filosofía natural actualmente en construcción desemboca, más allá del progreso en la modelización de los fenómenos, en una reestructuración de nuestra concepción de las relaciones entre 
lenguaje y realidad» (J. Petitot, 1966: 340).

Una mirada a los problemas del texto a través de ópticas diferentes no tiene por qué aportar forzosamente «algo nuevo», sino, muy por el contrario, confirmar lo ya conocido a través de otros enfoques y permitir el descubrimiento de apreciaciones distintas, así como favorecer aproximaciones escalares más flexibles, con el objeto de comprender mejor los complejos recursos de la lengua, sus turbulencias, equilibrios y organizaciones.

\section{Referencias bibliográficas:}

Barthes, Roland (1970): S/Z, París: Seuil.

Barthes, Roland (1973): Le plaisir du texte, París: Seuil.

Beaugrande, R. de \& Dressler, W. (1981): Introduction to Text Linguistic, London: Longman.

Bernárdez, Enrique (1995): Teoría y epistemología del texto, Madrid: Cátedra..

Borko, H. \& Bernier, C. L. (1975): Abstracting Concepts and Methods, New York: Academic Press.

Cifuentes Honrubia, J. L. (1994): Gramática cognitiva. Fundamentos críticos, Madrid: Eudema.

Cifuentes Honrubia, J. L. (1994-1995): «Teoría Semántica y Traducción», Estudios de Lingüística, 10, Alicante: Universidad de Alicante.

Cremmins, E. T. (1982): El arte de resumir, Barcelona: Mitre, 1985.

Dijk, T. A. van(1978): La ciencia del texto, Barcelona: Paidós Comunicación, 1983.

Feder, Jens (1988): Fractals, New York: Plenum Press, 1989 (4ª ed.).

Gómez, Juan Pedro (1991): «De los Preámbulos y Liminares Constitucionales como Metatextos (En el Texto Constitucional Hispanoamericano)», en Estudios de Linguística, 7, Alicante: Universidad de Alicante.

Gómez, Juan Pedro (1993): «Aspectos tipológicos del texto instructivo (A propósito del prospecto para medicamento de uso humano)», Estudios de Lingüística, 9, Alicante: Universidad de Alicante.

Gómez, Juan Pedro (1998): «El fenómeno del texto y la enseñanza de la lengua», en Homenaje al Profesor Muñoz Cortés, XVIII Curso de Lingüística Textual, 1995, Murcia: Universidad de Murcia.

Hatim, Basil \& Mason, Ian (1990): Teoría de la traducción. Una aproximación al discurso, Barcelona: Ariel, 1995.

Hjelmslev, Louis (1971): Prolegómenos a una Teoría del Lenguaje, Madrid: Gredos.

Lamíquiz, Vidal (1994): El enunciado textual. Análisis lingüístico del discurso, 
Barcelona: Ariel.

Mandelbrot, Benoît B. (1982): The Fractal Geometry of Nature, New York: W. H. Freeman.

Newmark, Peter (1987): Manual de Traducción, Madrid: Cátedra, 1992.

Peitgen, H. O., Jürgens, H. y otros (1991): Fractals for the Classroom: Strategic Activities, New York: Springer-Verlag.

Pérez, F. M. \& López, A. J. (1994-1995): «Para una formalización «topológica» de la semántica», Estudios de Lingüística, 10, Alicante: Universidad de Alicante.

Petitot, Jean (1966): «Ni siquiera un ángel... (El problema del surgimiento de lo descriptible a partir de lo indescriptible)», en El Tiempo y el devenir, a partir de la obra de Ilya Prigogine, Barcelona: Gedisa, 1966.

Pottier, Bernard (1975): Gramática del español, Madrid: Ediciones Alcalá.

Pottier, Bernard (1992): Semántica General, Madrid: Gredos, 1993.

Prigogine, Ilya (1972-1982): ¿Tan sólo una ilusión? Una exploración del caos al orden, Barcelona: Tusquets, Metatemas 3, 1993 ( $3^{\text {a }}$ ed.).

Propp, Vladimir (1977): Morfología del cuento, Fundamentos, Madrid.

Ramón Trives, Estanislao (1983) : «La lingüística integral y su incidencia en el aprendizaje de una lengua extranjera», en Actas del Primer Congreso Nacional de Lingüística Aplicada (AESLA), Murcia: Universidad de Murcia.

Thom, René (1977): Estabilidad estructural y morfogénesis, Barcelona: Gedisa, 1987.

Thom, René (1988): Esbozo de una semiofísica, Barcelona: Gedisa, 1990.

Vera, A. (1994): Fundamentos de análisis sintáctico (de la palabra al texto), Murcia: Secretariado de Publicaciones de la Universidad de Murcia.

Villegas, Juan (1973): La estructura mítica del héroe, Barcelona: Planeta.

Wagensberg, Jorge (1985): Ideas sobre la complejidad del mundo, Barcelona:

Tusquets, Superínfimos 3, 1989 ( $2^{\text {a ed.). }}$

Woodcock, A. \& Davis, M. (1989): Teoría de las catástrofes, Madrid: Cátedra. 